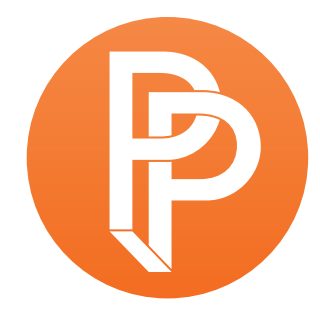

PERFORMANCE

PHILOSOPHY

\title{
ETHICS OF PLAY IN EARPIECE PERFORMANCES BY NATURE THEATER OF OKLAHOMA AND GOB SQUAD
}

\author{
FRED DALMASSO LOUGHBOROUGH UNIVERSITY
}

In Rhapsody for the Theatre, Badiou propped the notion of the ethics of play against a theory of the subject that had yet to be fully deployed. His reflection remains tentative and he simply suggests 'that the actor could very well show a subject without substance,' that 'always between-two, [the ethics of play] operates in the pure present of the spectacle, and the public [...] gains access to this present only in the aftermath of a thought,' and ultimately that 'the ethics of play is that of an escape' (Badiou 2008a, 216, 221). There is a delay at work in the ethics of play, an in-between. By looking at Nature Theater of Oklahoma's Life and Times and Gob Squad's Gob Squad's Kitchen (You Never Had It So Good), this article proposes to examine how an ethics of play could be materially deployed in these earpiece performances through the delay, albeit minimal, the in-between text or instruction and their actualisation on stage. NTOK's Life and Times and Gob Squad's Kitchen have little in common except for the fact that both performances rely upon the ability of performers or participatory audience members to convincingly speak lines and execute instructions received through wireless headphones. However, these similarities become meaningful when seeing the two performances through a Badiouan lens and very useful when it comes to explaining what Badiou's elusive notion of the ethics of play might entail. In this article, I revisit two theatre reviews I absent-mindedly wrote, or so it seemed at the time, while trying to come to terms with Badiou's notion of the ethics of play. My spectating was under influence, albeit of a philosophical nature and this article also assumes its own bias: after all, performance philosophy could also consist of taking concepts for an evening at the theatre and make them perform in a sort of play within a play. In hindsight, I was also perhaps unconsciously emulating Badiou's series of short pamphlets about theatre in Rhapsody for the Theatre in response to shows he had seen at the time. In his treatise, 
Badiou rehearses his ideas for the notion of the ethics of play within a three-pronged Theatre dialectics. However, he is more than reluctant to directly relate his newly forged concepts to specific performances and leaves this to the character of the Empiricist. While it also resists empiricism to a degree, this article will suggest how NTOK's Life and Times and Gob Squad's Kitchen could perform some of Rhapsody for the Theatre's dialectical tensions between the theatrical State, the ethics of play and the spectator-subject.

\section{A Theatre of presentation}

As a condition for a Theatre event to occur, Badiou's ethics of play is described in his Rhapsody for the Theatre as an escape from representation, but also from what he calls a "theatre of Presence". Badiou's words are lapidary on this: 'The Mass is worn out, the theatre of Presence is obliterated' (Badiou 2008a, 217). The ethics of play consists of the performer's ability to present existence as movement away from essence, from the innate, the inherent, the intrinsic. As opposed to theatre and its predetermined roles, Theatre (capital $\mathrm{T}$ ) is presented as the antithesis of the Catholic mass because it is not ruled by substantialism. Badiou stresses that what he considers to be bad theatre 'gives up on the ethics of play insofar as it distributes substances' (Badiou 2008a, 220). Moreover, the idea that the ethics of play goes against any theatre of Presence is in line with Badiou's transitory ontology. The concept of Presence (capital P) has to be understood here as it is being used by Badiou in Rhapsody for the Theatre in an analogy with the Catholic Mass in terms of substantialism and transcendence; while it might evoke certain aspects of it, it does not encompass the whole complexity of what the notion of presence has come to refer to in Performance Studies. For Badiou, any ontological investigation is irremediably localised and Theatre can only happen in the here and now of a materialised performance. Being as a global transcending entity or as an absent Presence or, in Heideggerian terms, "being in totality" is out of the question. He extracts a theorem of the non existence of 'total being' from the fundamental axioms of set-theory, which he sees as the principles of what he calls the ontology of the multiple: there is no set which contains all the sets. It is impossible to conceive a multiple, thus a being, which would be the aggregate of all the possible beings. Since for Badiou, being is also only by being-there, he brushes aside the question of the essence of being to focus on appearing as for him appearing is the site of being when conceived in all its multiplicity. Since the materialisation of being-there implies a situation, a site, appearing is what links or connects being to its site. Thus the essence of appearing is precisely that connection and not something predetermined by the situation or the site. In the case of Theatre, that connection is governed by the ethics of play. Within Badiou's Theatre dialectics, the ethics of play enables the spectator-subject to think the relation between the inconsistency of being as a pure multiple and the consistency of its appearing. For Badiou, accessing the idea of the pure multiplicity of being does not happen by 'shunning appearing, nor by singing the praises of the virtual [...] but by thinking appearing as appearing, and thus as this part of being, which happens to appear, and offers itself to thought as a deceit of seeing' (Badiou 2008b, 23). This is the reason why while he refutes a theatre of Presence, Badiou advocates a theatre of presentation. The aim of the ethics of play is precisely the provocation of presentation-not the presentation of being but that of appearing since according to Badiou's ontology, 'being does not in any manner 
let itself be approached, but solely allows itself to be sutured in its void to the brutality of a deductive consistency without aura' (Badiou 2006, 10). To provoke presentation, the ethics of play demands that actors resort to decisive bodily and vocal gestures. However, Badiou stresses that 'the central virtue of the actor is not technical but ethical' (Badiou 2008a, 219). Theatre's play of differences and the celebration of being as a multiple are not the main reasons why Badiou speaks of ethics. He explains that actors cannot rely upon effects-as these would equate acting to a straight imitation of an object or a caricature of predetermined roles, but upon gestures clearly signifying availability, an opening (Badiou 2008a, 219). He stresses that the ethics of play is only possible from the edge of the void, in other words, at the threshold of the absence of an object to imitate. The actor's provocation of presentation has to point to the out of joint nature of a world where 'nothing coincides with itself' (Badiou 2008a, 221).

In episode 1 of NTOK's Life and Times, everyday routine in a New Jersey suburban town is strangely conveyed on stage through Spartakiada inspired choreography drawing from a series of athletic exercises developed in Czechoslovakia and other Eastern Bloc countries for mass political celebrations. On stage, the ballet of red balls, white squares, blue scarves and yellow gymnastic rings creates visual jolts that combine with the prosodic and at times, operatic delivery of lines to hypnotic effect. The performers execute these movements with utmost precision following the instructions of a conductor. It seems that this choreography somehow answers to Badiou's imperatives in terms of the ethics of play. The performers' commitment to incessant instructions to perform such or such a movement does not confer them an auratic presence, but their incessant activity is mesmerising. However, they never embody the real-life character whose story they are telling, instead their industrious choreography of decisive bodily and vocal gestures resembles a technical assembly line that would disperse any notion of embodiment and yet provide the audience with the consistency of an absence or with the consistent failure to represent a life story. The playtext of NTOK's Life and Times is an edited version of a 16-hour phone conversation between Pavol Liska and Kristin Worrall, a member of the company during which Worral tries to answer the question: "Can you tell me your life story?" The performance shares most characteristics of headphone verbatim as defined by Caroline Wake:

\begin{abstract}
In headphone verbatim, the performance displays not only its source material but also the mechanical device needed to record and repeat that material. In both rehearsal and performance, the actors wear headphones, through which they hear the audio script. They then repeat that script as immediately and exactly as possible, including —as noted above-every stammer, pause, and repetition. (Wake 2013, 322-323)
\end{abstract}

However, Wake is reluctant to describe NTOK's work as headphone verbatim because their approach is not strictly documentary (Wake 2013, 330). In this, Wake agrees with Karinne Keithley who stresses that Copper does not 'simply "document" a nonfictional reality as documentary theatre might; rather, in collaboration with the company, she collects, transcribes, and orders linguistic data so that they may collectively energize it on stage' (Keithley 2010, 69). Although the text of Life and Times has been edited, it retains all the hesitations of the phone conversation and is punctuated by a large number of "ums" and silences. As argued by Rachel Anderson-Rabern, 
NTOK's work could be described as developing an awareness for ethical listening (AndersonRabern 2010, 96), however here their methods for recording, structuring and performing everyday gesture and language will be analysed as an ethics of play. When channelled through the headphones, these repetitive "ums", pauses and hesitations contribute to replicate the distance inherent to any phone conversation, but also to highlight the transmission delay, that is then reproduced when the text received through the earpiece on stage is then spoken. This also highlights the sense of the elliptical and of the unexpected that govern the piece.

As directors of NTOK, Liska and Kelly Copper have developed several techniques and dramaturgies of chance over the years and in this performance. In Life and Times, both randomly prompt the performers to reproduce rehearsed gestures or sequences of movements. Copper is conducting the performers from the orchestra with a set of instructions displayed on cue-cards not visible from the auditorium, while Liska assigns lines to the performers through their earpiece. Following John Cage and Richard Foreman, there is in fact no work by NTOK that was not written in large part with dice, decks of cards or coins. However, as Florian Malzacher stresses 'chance is not completely arbitrary. Rather it is something that comes to you and then in a sense belongs to you. Something that one must view as a challenge and which demands flexibility of thought. Leaving certain decisions to chance does not equal less work; it merely shifts the focus' (Malzacher 2012, 19). In Inaesthetics, Badiou asserts that 'a theatrical representation will never abolish chance' and in Rhapsody for the Theatre, that 'the paradox of theatre [...] lies in the fact that it presents itself as a figurative luxury, a solid chain, a cultural temple, but [...] it is actually made of flight and chance' (Badiou 2004, 74 and 2008a, 199). Within Badiou's Theatre dialectics, the ethics of play ensures that chance is allowed to disrupt the system of representation, while in his theory of the event, fidelity 'names a process that separates and discerns the becoming legal of chance' (Riera 2005, 12). Chance becomes the rule when the evental subject has decided upon the undecidable inherent to the event to choose a new law to follow. To an extent, Badiou's Rhapsody for the Theatre announces his theory of the event since the ethics of play might well ensure the becoming legal of chance when it comes to the Theatre event. To an extent, the actor's ethical availability that Badiou insists upon, amounts to an ethical opening to chance and consequently to the endless possibilities and configurations of the new.

Life and Times might not be a staged attempt to recollect someone's life story by excavating and ordering past experiences, but a discourse on chance and existential randomness. On stage, performers appear extremely focused and at the same time totally lost as they are literally kept on their toes by the quick succession of random and at times, contradictory instructions they are meant to follow. In her review of the performance, Helen Shaw remarks that 'we see their anxious micro-expressions as their eyes slew to the prompter, checking for the next move' (Shaw 2013, 5). Although the performers draw from a well-rehearsed repertoire of actions, they are constantly on the edge especially when they serve food to the entire audience at every interval or in a more comic fashion in episode 3, when they are forced to swap the lines of Agatha Christie's play The Mousetrap for the lines of the performance's telephone conversation verbatim transcript, while staying in The Mousetrap's stereotyped characters when it comes to expressions and movements. This melodramatic atmosphere is suddenly disrupted by the apparition of silver body-suited aliens 
armed with giant party popper guns. Malzacher explains that when 'it becomes apparent that an actor has developed patterns or strategies for saving himself, that effort must be thwarted. Salvation is boring and the bar is steadily set higher through, for example, continually inserting new dances into a piece. Being over challenged is not an imperfection but rather intentional' (Malzacher 2013,5). The restless agitation and volubility of the performers cannot disguise the fragmented nature of the narrative nor its explicit randomness. As pointed out by Jacob GallagherRoss, audience members are 'constantly reminded of the gaps, the fissures, the forgotten or poorly recollected people. The pointillist particularity of the memories Worrall has managed to keep only gestures to the vast swathes of time and experience forever lost to her (or any of us)' (GallagherRoss 2012, 70). During the performance, we are constantly reminded of the obvious, but no less painful, impossibility to tell a life story in its entirety. NTOK develop in fact a complex dramaturgy of ellipses as their performance unfolds in a syncopated mode. In Life and Times episode 1, the text appears as supertitles on two screens while the performers sing the lines they are being fed through earpieces. Shaw remarks that 'ripples of laughter move through the audience as the droll, uninflected "voice" of the supertitles elevates what happens below into an opera-and since we read faster than they can sing-syncopates our response to it' (Shaw 2013, 5). There are thus two levels of syncopation in the performance: the one directly experienced by the audience reading then listening and the one spectators experience in the form of a brief delay when watching performers processing the lines they receive through their earpieces before uttering them.

Copper stresses that Life and Times 'is not meant to be an all encompassing biography-or even a biography, for that matter' and that they use the first person account as 'a lens for a more enlarged consideration of self, community, and history.' (Copper 2013,7) When Worrall names herself in the text, other performers use their names instead and Copper stresses that 'though the language in Life and Times is all first-person singular, the "I" in performance is very much plural' (Copper 2013, 7). Remembering is presented as an activation of compossible experiences. As pointed out by Shaw, 'for some, the multiplying voices emphasize a kind of choral sensation that those on stage are repeating our own private, often embarrassing memories' (Shaw, 2013, 6). This is even more striking that most of the audience members' childhoods have in theory very little to do with growing up in a New Jersey suburban town. What is being drawn over the 12 hours of the performance is a multi-layered memory map where we are left to wander, backtrack and which ultimately leads us to address our own apparently forgotten childhood and teenage years. There are recurrent names or narrative motifs which provide some bearings within the epic tale, but also moments where the narration seems to hit a dead-end or an incommensurable gap: for example there are several mentions of the child staring at 'mum' cooking through the bars of a wooden bench's back or staring at the rug and saying with the nostalgic tone of an ineluctable loss "I need to remember this moment for the rest of my life." Paradoxically, these moments have the soothing effect to reiterate the randomness of memory and qualify as worth remembering moments that could have on the contrary seemed insignificant at the time. Rather than a life story, we are presented with flashes of experience that in turn trigger our own and we are encouraged to open the floodgate of long neglected but now revived memories. This collective act of remembering is enabled by the emphasis placed on hesitations and syncopations in the performance that invites spectators to delve into their own past. In the words of Jean Luc Nancy, NTOK's dramaturgy of syncopation 
generates 'the emptiness or the opening of this space-its very spatiality or its many spacings (espacements): it is the place of our compearance' (Nancy 1992, 373). The ethics of play at work in NTOK's Life and Times fractures the theatrical state, that is, a system of representation conventionally ruled by the projection of an alleged inner self upon predetermined categories. The ethics of play calls for an escape from the self into the collective by inscribing the spectator-subject in the syncopated time of the delay between instruction and action, between interpellation and commitment. In Gob Squad's Kitchen (You've Never Had It So Good), Gob Squad resort to earpieces to develop a strategy similar to that deployed by NTOK. However, the complexity of Gob Squad's apparatuses to create "spacings" makes the place of compearance they generate very interesting to analyse.

\section{A performance of spectrality}

Gob Squad's Gob Squad's Kitchen (You've Never Had It So Good) is an attempt at a live re-enactment of Andy Warhol's filmed performance Kitchen. 'This reconstitution of the $60 \mathrm{~s}$ is presented as a demystification: the film projected to the audience is shot live behind the screen that becomes more porous a barrier as the piece unfolds. Ultimately performers ask audience members to stand in for them "guess-performing" the original Kitchen and, as if by magic, the "volunteers" suddenly exude a screen/stage presence, which transcends technology and demonstrates the mysterious power of theatre's immediacy' (Dalmasso 2011, 32). These hasty comments have been calling for some explanation for some time and I would now like to explain what I could have meant when reviewing this show. When referring to a mysterious immediacy, I probably had in mind what Jacques Derrida defines as 'a spectral moment, [as] a moment that no longer belongs to time, if one understands by this word the linking of modalized presents (past present, actual present: 'now', future present' (Derrida 1994, xx). What Gob Squad achieve overall in Kitchen is to recreate moments in time, that of the original Warhol films Kitchen, Kiss and his series of Screen Tests. Gob Squad performers repeatedly say "this is real", that they are "in the moment" or even "full of the moment" while also continuously pointing to their incapacity to be other than themselves performing themselves and to the difficulties to be themselves then, that is while impersonating Warhol's performers in May 1965 when the original Kitchen was filmed (Gob Squad 2011). Gob Squad's Kitchen could be described as a playful experience of spectrality. It is not so much Warhol's actors who haunt Gob Squad performers, it is more their everyday selves haunting themselves as performers trying to impersonate the original Kitchen performers. Although commenting upon their creative process throughout, the performers do not of course talk in terms of spectres or spectrality. As Derrida would remark, you probably would have to be an academic, a scholar to 'be capable beyond the opposition between presence and non-presence, actuality and inactuality, life and non life, of thinking the possibility of the specter, the specter as possibility' (Derrida 1994, 12). Gob Squad's Kitchen raises issues in terms of the interaction between two different types of spectral materiality-that of the stage and that of the screen, and in terms of the shift between projected and non-projected appearance throughout the performance. To an extent, it is possible to describe what happens on stage as an interaction between two different intensities or two materialities of appearance. Supposing that there is a difference, a shift, a movement between two 
intensities of appearance, this invokes the possibility of a spectre or the spectre of a possibility: precisely that of a spectre able to move from one world or materiality to another and/or that of what is impossible in one world to become possible in another. In any case, Gob Squad's Kitchen presents us with a porous moment, a disjointed time between the now of Gob Squad's performance and the now of Warhol's 1965 film.

By playing with the theatricality of the spectral, Gob Squad provide us with an aesthetics and a stage configuration to observe the dialectics at work between stage and screen, theatre and cinema. Their dramaturgy creates a dialectical space in between different materialities of performance or intensities of appearing through constant shifts from one 'world' to another. However, it remains difficult to bridge the gap and precisely explore the dialectical movement between the cinematic and the theatrical as a shift between two modalities of performance or two different intensities of existence. There is also the risk of adopting a dialectical standpoint that might ultimately send theatre and cinema back to back and fail to do justice to the trespassing spectres. Yet, 'the dividing line between the ghost and actuality ought to be crossed' (Derrida 1994, 38) and this is largely what Gob Squad do, simply because by inviting audience members to stand in for performers joyfully failing to embody Warhol's screen personae, Gob Squad's Kitchen opens up a possibility for anybody in the audience to encounter their own spectre in the form of a potential different self, perhaps even a potential other within themselves. This is not simply hinted at, or pointed at, but this potentiality is materially created on stage by precisely materialising a screen appearance and transferring an image upon a three-dimensional stage. And this works on many levels: Gob Squad live performers attempt to embody and flesh out, so to speak, the 1965 celluloid performers in Warhol films, then Gob Squad performers become celluloid, then dematerialised as mere voices whispering through headphones as they are in turn embodied by audience members. It is precisely the multiplication of bodies, the repetition of the embodiment process that creates this possibility for spectres. However, this embodiment paradoxically seems to equate dematerialisation and desynchronisation as each level of performance implies a degree of disappearance. This is the case for Gob Squad performers disappearing backstage behind a screen for their image to be projected to the audience; this is also the case for the audience members disappearing backstage behind the screen or when on stage behind the headphone apparatus as their movements are dictated by Gob Squad performers acting like remote puppetmasters. However, the embodiment is not unilateral, there is a constant back-and-forth between embodied and embodying creating a movement of diffused origin. The time is out of joint and after a while we are unsure of where the performers are and of who is haunting whom. There is a crossing of several worlds: that of 1965, that of performers live on screen re-enacting Warhol's film, that of the same performers performing themselves on screen and on stage, that of the audience members, that of audience members impersonating performers, that of performers becoming audience members, etc. This movement across realities creates the possibility of a crossing and consequently a spectral possibility or potentiality. What remains striking with Gob Squad is the importance they attach to the materiality of their creative process. Audience members enter backstage and as they make their way through to the auditorium behind a massive screen, they walk through the film set but also among cameras, wires and other filming apparatuses. This invitation to materially take part in the performance culminates, when in their attempt to recreate 
Warhol's Kitchen, Gob Squad performers gradually replace themselves by audience members one after the other as a last resort and declare that they cannot reproduce the 'aura of the people in the original film' (Gob Squad 2011). However it is not a simple reversal of places. Audience members literally stand in for them, being told what to do and say through big headphones that are not disguised. However, despite the artifice being over exposed, as their images appear on the screen, the volunteered audience members seem to suddenly exude an uncanny presence. What occurs towards the end of Gob Squad's Kitchen seems to exceed the aims of participatory theatre in terms of audience involvement. Here, the performers are not only replaced, but audience members achieve what performers could not. As they appear on the screen, their image is constructed so as to evoke the improvised 'auratic presence' of the original Warhol performers. More precisely, Gob Squad builds a sense of expectation until that point in the performance and it is undeniable that when the audience members replace the performers, something happens. They appear as believable embodiments of the original Kitchen's real characters. This transformation has been prepared by the script and by Gob Squad performers' intentional repetitive failed attempt to achieve the detached self-consciousness allegedly displayed in Warhol's original film. Not only the volunteered audience members seem to exude a particular presence, but somehow they seem suddenly more 'present'-read granted a higher intensity of appearance-than Gob squad performers. One might argue that the audience members are non-performing and that in itself might 'present' something beyond the performers' reach, and perhaps we might be touching upon "the real" Gob Squad performers claim to be the object of their performance quest throughout (Gob Squad 2011).

In Warhol's original films used as a basis for Gob Squad's re-enactment, be it Kitchen, Kiss, Eat, Sleep or the Screen Tests, the performers are asked to act as if the camera was not there. In fact, it is well documented that for part of the Screen Tests, Warhol pretends to go and make a coffee and does not tell the person he is filming that the camera is rolling. David James argues that the camera is a presence and under its gaze and against its silence the person must construct herself or himself. He insists that because the camera 'makes performance inevitable, it constitutes being as performance' (James 1989, 69). While in Warhol's Kitchen, performers ignore the camera, escape from its glance and pretend it is not there, the contrary occurs in Gob Squad's Kitchen where everything is performed for the camera, in fact for the audience watching the big screen separating them from the performers performing live backstage. Most of the time, instead of being (or pretending to be) oblivious of the camera, Gob Squad performers alternate in fact between pretend self-consciousness and pretend non self-consciousness in front of the camera. However, when the audience members perform, they are given more instructions, more lines to repeat and there seems to be very little room or time for self-consciousness. They have very little leeway to perform themselves performing Kitchen as Gob Squad performers did. The audience members do not perform but they are performed upon; they become material for performance not performers. With Gob Squad's Kitchen, we are definitely dealing with being-there and appearing: the beingthere of theatre, the appearing of cinema and potentially vice-versa. If only because of the use of a screen as a mediator between the live performance happening backstage and the audience, it would be tempting to analyse Gob Squad's performance in terms of a screen 'presence' overtaking that of performers on stage. In fact, the audience members receive instructions through 
headphones, they are prompted to say such and such lines and as such they are rather overperforming. And yet something shifts in the modality of performance. This might be simply the result of a higher degree of appearing intensities. Perhaps audience members turned performers seem more materially here as they are grounded by instructions and cumbersome headphones. In any case, the syncopated rhythm of the lines delivery due to the delay in transmitting what they are fed through headphones inscribe the audience members turned performers in a time slightly out-of-sync or out-of-joint.

In Gob Squad's Kitchen, the camera creates a relation to the site that at first sight does not seem to be predetermined in the sense that it allows the performance to invent a new relation to the sitea life-performance situation including live footage, and thus to reveal a new site, that of an intersection or conflagration of different past, present and possibly future worlds. Nevertheless in Gob Squad's re-enactment of Warhol's filming session, the way the camera inadvertently captures "being as performance" is far from being completely non-predetermined (James 1989, 69). Every plan has been carefully thought through even when there is scope for improvisation at particular moments and even if Gob Squad's performers cannot fully control the audience members turned performers. However, paradoxically it seems that the use of earpieces and the delay between instruction and execution, or live directing and acting, resets the audience's expectation of the unexpected. Suddenly, in these suspended fractions of a second, it is as if the cumbersome apparatus becomes invisible and leaves space for the unpredictable.

\section{Ontological delay and inexist[a]nce}

According to Badiou, 'Being does not diffuse itself in rhythm and image, it does not reign over metaphor, it is the null sovereign of inference' (Badiou 2006, 10). By rhythm Badiou refers here to repetition and this remark has to be understood in relation to the idea explained earlier that being is necessarily subtracted from representation-a subtraction that can only be grasped in the materiality of being-there that precisely reveals the void of a situation, its underpinning vacuum, as the substratum of being. However, following French linguist and philosopher Henri Meschonnic, rhythm could be defined not as a regularity of similar intervals or recurrences, based on repetition, periodicity and measure, but as dispositions or configurations without any fixedness or natural necessity and resulting from an arrangement that is always subject to change. Meschonnic sees rhythm as a subjective configuration of meaning in the discourse, as the mark of the subject (Meschonnic 1982, 70). Similarly, if rhythm is defined not as the regular recurrence of the same but as what eludes repetition and points to the void through for example, syncopation, then any presentation of a gap, of a delay could be considered ontological. According to an ethics of play turned ethics of appearing, the site of appearing would not be the body of the performer or participants. It is the gap or delay in between the instruction given through the earpiece and its execution that would give consistency to appearing and thus provide the substratum for performance. To an extent, it would make sense to suggest that in the case of Gob Squad's Kitchen and NTOK's Life and Times, the site where being 'allows itself to be sutured in its void to the brutality 
of a deductive consistency without aura', is the connection, the interplay, the delay, the gap, the void (Badiou 2006, 10).

In the case of Gob Squad's Kitchen and NTOK's Life and Times, what happens to appear in the gap provided by the delay is a haunting, an inexist[a]nce that surges forth from the void of representation. In NTOK's Life and Times, this is only possible because representation is fractured to allow the coincidental emergence of other possibles through the syncopated performance. Between screen and stage, the dramaturgy of Gob Squad's Kitchen also generate "many spacings" to create a place of "compearance", in that case, space for a collusion of performers and audience members through a restless mirroring of different performance moments (Nancy 1992, 373). For Badiou, Theatre (capital T), does not give substance to differences and 'turns every representation, every actor's gesture, into a generic vacillation so as to put differences to the test without any supporting base' (Badiou 2008a, 219-220). No absolute reference is required to effect a differentiation, to install a distance. This is the reason why the actor abiding to the ethics of play does not need an object to imitate, but needs to present a constant minimal self-distancing. I would like to suggest that the function of the delay is to create the possibility for a syncopated self. This gap in the performance ensures that nothing exactly coincides with itself and points to the perpetual resetting or deferral of any referent and ultimately to the possibility for the radical new to emerge, for the impossible to occur. Badiou describes in fact the ethics of play as 'an inauguration of meaning' and for him, Theatre (capital T) 'presents differences as objectless transparencies' and 'does not exist except in the act itself' (Badiou 2008a, 220). There is no ground for differences, they just appear as such in action. This is what Badiou means when he writes that 'theatre proposes to us a signification of supposed substances, and Theatre (capital T), a procedure exhibiting generic humanity, that is to say, indiscernible differences that take place on stage for the first time' (Badiou 2008a, 220). Acting becomes ethical not by erasing all differences but by pointing out the arbitrary nature of any marker of difference, and thus by showing on stage the 'evaporation of every stable essence' (Badiou 2008a, 221). The ethics of play precisely consists of an escape from any system of representation, or differentiation. The delay at work in the transmission of lines serves as a reminder that what grounds performance is precisely that opening onto the perpetually same but different and not a closing down in different categories. This resonates with the way both NTOK and Gob Squad work. For Badiou, actors have to literally engage in a play. Like in the original éthique du jeu, the English term "play" refers as much to a game as to acting. For Badiou, there is 'a cogito of the actor [...]: I am not where one thinks that I am, being there where I think that one thinks that the other is' (Badiou 2008a, 216). This is also the paradox of the actor as defined by Badiou to point to what subtracts itself, to present the void, to signify an opening, but also an availability. For the actors, the ethics of play consists of playing an endless hide and seek game as much with themselves as with the audience and this is precisely what happens in Gob Squad's Kitchen and Life and Times. According to Badiou's definition of existence, there are only fluctuating degrees of appearing in a given world, variable intensities of being-there. His conception of Theatre supports this and, to an extent, it seems that in the case of the two earpiece performances under scrutiny here, life lets itself only be approached as a delay, a syncopation, a hiatus, a subtraction, an inexist[a]nce. 
Syncopation is at the core of the shift in Badiou's theory of the subject from a political subject identified as 'We' or 'l' to a subjective instance which is precisely what is not supposed to exist and which bears the mark of the exception, that is, a subject whose affirmation takes the form of a hiatus, a void, a grammatical incision. In Logics of Worlds, Badiou explains that the subject resides in:

\begin{abstract}
the "aside from", the "except that", the "but for", through which the fragile scintillation of what has no place to be makes its incision in the unbroken phrasing of a world. "What has no place to be" should be taken in both possible senses: as that which, according to the transcendental law of the world (or of the appearing of beings), should not be; but also as that which subtracts itself (out of place) from the worldly localization of multiplicities, from the place of being, in other words, from being-there. (Badiou 2009d, 45)
\end{abstract}

Badiou's theatre articulates the subject in such a manner that it follows the theoretical shift from a named subject to a subject marked by inexist[a]nce. The ethics of play conceived as an escape in Badiou's Rhapsody for the Theatre seems to rehearse the notion of inexist[a]nce developed in his more recent Logics of Worlds. For Badiou, inexist[a]nce is a mode of existence: existence measures the degree of appearance of an object in a world: inexist[a]nce being the minimal degree of appearing in a world (Badiou 2009d, 322). To an extent, he derives the notion of inexist[a]nce from Derrida's notion of différance. For Badiou, inexist[a]nce is a materialist 'worldly way of non-existing' (Badiou 2009c, 144). In Pocket Pantheon, Badiou explains that what is at stake in Derrida's work is 'the inscription of the non-existent' and the recognition that such an inscription is impossible. Endorsing Derrida's approach, Badiou stresses 'You must demonstrate the vanishing point by making language free. You must have a language of flight. You can only organise a monstration of the non-existent if you use a language that can stand non-existing' (Badiou 2009c, 144). Badiou's ethics of play conceived as an escape from representation provides if not a language of flight, at least a dispositive to account for what inexists in a world. In this respect, the transitory nature of politics is precisely what is at stake in Badiou's ethics of play insofar as politics is defined as 'the art of the impossible' (Badiou 2009a, 317). For Badiou, politics has 'value only insofar as it prescribes a "possibility" for a situation that the immanent norm of this situation defines precisely as impossible' (Badiou 2009b, 48). In other words, for Badiou politics occurs when what was not given any place in a given situation, suddenly comes to the fore. Badiou considers different degrees or intensities of existence in a given world or situation and ultimately equates true politics to the raising up of the inexistent, that is, the emergence in a given situation of what was not deemed possible (Badiou 2011, 80). Within Badiou's philosophical system it is the notion of inexist[a]nce that seems to be the most closely related to the ethics of play because inexist[a]nce is also of a transitory nature. In terms of performance, the ethics of play ensures the creation of a gap, a delay, and that space is made for 'what has no place to be' and to an extent, this is what relates the headphone dramaturgies of Gob Squad's Kitchen and NTOK's Life and Times to politics as defined by Badiou.

To conclude, Badiou's notions of ethics of play and inexist[a]nce delineate a non-space, a void that seems to materially appear in Gob Squad's Kitchen and NTOK's Life and Times through the delay 
rendered manifest by the headphone dramaturgies. In NTOK's Life and Times, the dissemination of suburban life fragments through headphone transmission creates an aesthetics of the everyday detached from its representation. Because of the transmission delay, the real life narrative is opened up and remembering is presented as an activation of choral compossible experiences. As for Gob Squad's Kitchen, it blurs the boundaries between performance and non-performance, but the transmission delay empowers the audience members turned performers and consequently the whole audience to embrace the possibility not only of a reversal of places on stage and beyond, but to consider the possibility for the destruction of the system of places, for the raising up of the inexistent. This is in line with the way, in Badiou's Rhapsody for the Theatre, the ethics of play emancipates spectator-subjects towards the collapse of the theatrical state.

\section{Works Cited}

Badiou, Alain. (1998) 2004. Handbook Of Inaesthetics, translated by Alberto Toscano. Stanford: Stanford University Press.

_-_- (1988) 2006. Being and Event, translated by Oliver Feltham. London and New York: Continuum.

___. (1990) 2008a. Rhapsody for the Theatre: A Short Philosophical Treatise, translated by Bruno Bosteels. Theatre Survey 49 (2): 187-238. https://doi.org/10.1017/S0040557408000124

___. (2003) 2008b. 'Dialectics of the fable', translated by Alberto Toscano. Science Fiction Film and Television 1 (1): 15-23. https://doi.org/10.3828/sfftv.1.1.3

___. (1982) 2009a. Theory of the Subject, translated by Bruno Bosteels. London and New York: Continuum.

___. 2009b. L'Antiphilosophie de Wittgenstein. Caen: NOUS.

___. (2008) 2009c. Pocket Pantheon, translated by David Macey. London and New York: Verso.

___. (2006) 2009d. Logics of Worlds: Being and Event, Vol. 2, translated by Alberto Toscano. London and New York: Continuum.

Copper, Kelly, Florian Malzacher, and Nature Theater of Oklahoma. 2013. Life and Times, Episode I. New York: 53rd State Press.

Dalmasso, Fred. 2011. 'Neat Festival - Gob Squad's Kitchen (You Never Had It So Good).' Total Theatre 23 (3): $32-33$. Derrida, Jacques. (1993) 1994. Specters of Marx. New York: Routledge.

Gallagher-Ross, Jacob. 2012. 'This is your life'. PA): A Journal of Performance and Art 34 (3): 63-70. https://doi.org/10.1162/pajj_a_00112

Gob Squad. (2007) 2011. Gob Squad's Kitchen (You Never Had It So Good). Nottingham Contemporary, 30 May. James, David. 1989. Allegories of Cinema: American Film in the Sixties. Princeton: Princeton University Press. Keithley, Karinne. 2010. 'Uncreative Writing: Nature Theater of Oklahoma's Romeo and Juliet'. Theater 40 (2): 66-73. Malzacher, Florian. 2012. 'Previously on Nature Theater of Oklahoma' in Life and Times - Episode V, 113-128. New York: Nature Theater of Oklahoma.

Meschonnic, Henri. 1982. Critique du rythme. Anthropologie historique du langage. Lagrasse: Verdier.

Nancy, Jean-Luc. 1992. 'La Comparution /The Compearance: From the Existence of "Communism" to the Community of "Existence"", translated by Tracy B. Strong. Political Theory 20 (3): 371-398. https://doi.org/10.1177/0090591792020003001 
Nature Theater of Oklahoma. 2013. Life and Times. Norwich Arts Center, 25 May.

Riera, Gabriel. 2005. Alain Badiou: Philosophy and Its Conditions. Albany: State University of New York Press.

Shaw, Helen. 2013. 'Total Dedication: Nature Theater of Oklahoma's Life and Times, Episodes 1-4.' TheatreForum 43: 3-9.

Wake, Caroline. 2013. 'Headphone Verbatim Theatre: Methods, Histories, Genres, Theories'. New Theatre Quarterly 29 (4): 321-335. https://doi.org/10.1017/s0266464X13000651

\section{Biography}

Fred Dalmasso is Lecturer in Drama in the School of Arts, English and Drama at Loughborough University. He has published on practice-based theatre-translation and on the interaction between theatre, performance, philosophy and politics. Among his recent publications are a chapter entitled 'Remote Spectating - Drone Images and the Spectacular Image of Revolt' in Fisher, Tony and Katsouraki, Eve (eds.) Performing Antagonism (Palgrave Macmillan, 2017) and an edited book entitled Syncope in Performing and Visual Arts (Le Manuscrit, Via Artis, 2017). He is also a practitioner and works as artistic director and performer for collect-ifs.

(c) 2017 Fred Dalmasso

cc) (i) Except where otherwise noted, this work is licensed under a Creative Commons Attribution(c) NonCommercial-ShareAlike 4.0 International License. 